\title{
The Role of Extracellular Secreted Proteases and Phospholipases Enzymes in Differentiation Between Pathogenic and Non-Pathogenic Candida.
}

\author{
Mohammed M. Gheit ${ }^{1 *}$, Marwa A. Abd Elwahab², Tarek M. Mohamed ${ }^{1}$. \\ Corresponding Author: \\ Mohammed M. Gheit \\ Daier El-naheia Street, Tanta, Gharbya governorate, post number: 31527 \\ Mobile: +201280618550 \\ E-mail:mm_gheit@yahoo.com
}

1Chemistry Department, Biochemistry division, Faculty of Science, Tanta University, Tanta 31527, Egypt

2 Departments of Medical Microbiology \& Immunology, Faculty of Medicine, Tanta University, Tanta, Egypt

\begin{tabular}{|c|c|}
\hline ARTICLE INFO & ABSTRACT \\
\hline $\begin{array}{l}\text { Keywords: } \\
\text { pathogenic candida, protease, } \\
\text { phospholipase, Sabouraud dextrose } \\
\text { agar, C.albicans, C. glabrata. }\end{array}$ & $\begin{array}{l}\text { The genus Candida contains approximately } 200 \text { species. All humans are } \\
\text { colonized with Candida species, mostly Candida albicans, yet some } \\
\text { develop diseases due to Candida, among which genitourinary } \\
\text { manifestations are extremely common. The aim of this study was to } \\
\text { differentiate between pathogenic and non-pathogenic Candida according } \\
\text { to extracellular protease and phospholipase activities. Specimens were } \\
\text { cultured on Sabouraud dextrose agar for } 24 \mathrm{~h} \text { then sub cultured on } \\
\text { Sabouraud dextrose broth for } 24 \mathrm{~h} \text { at } 37 \text { oC, then the broth media was } \\
\text { centrifuged and the enzyme activity was determined in the supernatant. } \\
\text { Five pathogenic isolates were checked quantitively for their ability to } \\
\text { produce different extracellular enzymes. Purified C.albicans had } \\
\text { maximum protease activities ( } 105.67 \pm 3.66 \mathrm{U} / \mathrm{ml} / \mathrm{hr}) \text {. The other } \\
\text { pathogenic species showed an extracellular protease activities range from } \\
\text { ( } 86 \pm 2.7 \text { to } 100.75 \mathrm{U} / \mathrm{ml} / \mathrm{hr}) \text {. Purified C. glabrata had the maximum } \\
\text { phospholipase activities }(2.64 \pm 0.192 \mu \text { mol/hr) while other pathogenic } \\
\text { species showed an extracellular phospholipase activities rang from (1.62 } \pm \\
0.21 \text { to } 2.28 \pm 0.156 \mu \text { mole/hr). On the other hand, extracellular protease } \\
\text { and phopholipase enzymes had significant lower activity in the non- } \\
\text { pathogenic species. So, the extracellular proteases and phospholipase } \\
\text { activity could be used as a diagnostic tool to differentiate between } \\
\text { pathogenic and non-pathogenic Candida. }\end{array}$ \\
\hline
\end{tabular}

\section{INTRODUCTION:}

The incidence of invasive mycosis has increased due to the greater number of people suffering from predisposing condition, such as: organ transplant recipients, patients with AIDS and other immunocompromising conditions, lowbirth-weight newborns, patients with a history of prolonged antibiotic exposure, critically ill patients requiring multiple catheters or patients with cancer [1]. In humans, Candida is a part of the commensal flora and at the same time it is defined as a pathogen that causes opportunistic infections [2]. Candida infections are the leading cause of the

\footnotetext{
Corresponding Author: Dr. Abeer M. Ashmawy, Ph.D.

Professor of Biochemistry \& Molecular Biology, National Cancer Institute, Cairo University

Fom El-Khalig Street, Cairo 11796, Egypt.

Telephone: +202-01222789564

Fax: $\quad+202-23644720$

E-mail: Abeermanci@yahoo.com
} 
morbidity and mortality in the hospitalized patients [3]. The opportunistic pathogen Candida albicans is considered to be the most virulent Candida species. Two main factors predispose to infections with Candida spp.: i) colonization of skin and mucous membranes and ii) alteration of natural host barriers (wounds, surgery, and insertion of indwelling intravascular and urinary catheters)[4]. Several putative virulence factors of $\mathrm{C}$. albicans have been described, including secreted hydrolytic enzymes [5]. Two types of secreted enzyme seem to be the most important: phospholipases and secreted proteinases [6]. Secretory proteinases constitute a family of enzymes that are able to degrade several physiologically important substrates [7]. Many host proteins are hydrolyzed by secreted proteinases, including collagen, laminin, fibronectin, mucin, salivary lactoferrin, $\quad \alpha 2$ macroglobulin, almost all immunoglobulins, the proinflammatory cytokine interleukin-1 $\beta$, lactoperoxidase, cathepsin $\mathrm{D}$, complement, cystatine $\mathrm{A}$, and precursors of several blood coagulation factors [8].

Moreover, extracellular phospholipases degrade phospholipid constituents of host cell membrane leading to disruption of host cells or alteration of surface characteristics that facilitate adherence and subsequent infection [9]. The activity of phospholipases is very high during tissue invasion, because these enzymes are responsible for hydrolysis of one or more ester linkages of glycerophospholipids, of which the cell membrane is built [10].

The aim of the present study was to detect the pathogenic candida according to extracellular phospholipase and protease activities.

\section{MATERIALS AND METHODS:}

The study included 30 patients admitted to emergency ICU unit, Radiotherapy, and Urology Departments of Tanta University Hospitals. This study was approved by the ethical committee of Faculty of Medicine, Tanta University. Urine samples were collected by midstream urine (MSU) techniques or via indwelling urinary catheters from the patients with manifestation of urinary tract infections (UTIs). Non-pathogenic Candida samples were collected by a sterile cotton swabs from normal individual by the direct swabbing of the oral cavity. All Samples were collected and transported immediately to Medical Microbiology \& immunology Department of Tanta Faculty of Medicine.

\section{Processing and identification of samples Direct microscopic examination:}

Wet mount examination: deposits of urine were mounted in $10 \% \mathrm{KOH}$ and examined microscopically. Then, direct smear stain: Stained by Gram stain for detection of yeast cells, budding cells or pseudo hyphae

\section{Culture and morphological identification of Candida species:}

All collected specimens were inoculated directly on Sabouraud dextrose agar (SDA) (Oxoid, England) with chloramphenicol $(50 \mathrm{mg} / \mathrm{L})$ and incubated aerobically for $24 \mathrm{hrs}$ at $37^{\circ} \mathrm{C}$ [11]. Colonies suspected to be Candida were identified morphologically by Gram stain. Then germ tube test carried out to differentiate between $\mathrm{C}$. albicans and nonalbicans Candida.

Corn meal agar (Belami Fine Chemicals, Mumbai, India) with $1 \%$ Tween 80 (Sigma-Aldrich, USA) was used for cultivation and differentiation of Candida species [12]. Colonies identified as Candida on SDA were then sub cultured on CHROM agar (CHROMagarTM Candida, Paris, France) and incubated for 48 hours at $37^{\circ} \mathrm{C}$. Then sub cultured on Sabouraud Dextrose Broth for $24 \mathrm{hrs}$. Followed by centrifugation at $3000 \mathrm{rpm}$ 
for $10 \mathrm{~min}$ at $4 \mathrm{oC}$ to separate supernatant for enzymes activity assay.

\section{Biochemical Identification}

Was performed for Candida species identification using API $20 \mathrm{C}$ AUX Yeast identification system (BioMerieux, Marcy l'Etoile, France)

\section{Determination of protease activity}

The protease activity was determined according to (Leighton et al., 1973) with some modification. One $\mathrm{ml}$ reaction mixture of test consisting of 200 $\mu \mathrm{l}$ enzyme solution and $200 \mu \mathrm{l}$ of $0.1 \mathrm{mg} / \mathrm{ml} \mathrm{BSA}$ and $500 \mu \mathrm{l}$ of $0.05 \mathrm{M}$ phosphate buffer $\mathrm{pH} 7$ incubated for 30 min at $37^{\circ} \mathrm{C}$, Control was carried out. The reaction was stopped by adding $2 \mathrm{ml}$ of $10 \%$ TCA. The reaction was centrifuged after $15 \mathrm{~min}$ at $3000 \mathrm{rpm}$ for $10 \mathrm{~min}$. Protein was determined of the supernatant by Lawry (Lawry 1967). One protease unit was defined as the amount of enzyme that cleaved 1 nmole of BSA to tyrosine and other amino acids per hour under standard assay conditions.

\section{Determination of phospholipase activity}

Phospholipase activity was determined according to (Reagent chemicals ACS specifications, 8th ed., 95. (1993) with some modification using lecithin as substrate. Using a suitable $\mathrm{pH}$ meter in conjunction with a magnetic stirrer, pipette (in milliliters) the following reagents into a suitable titration vessel, $2 \mathrm{ml}$ of lecithin emulsion putted in tube, then $0.5 \mathrm{ml}$ of tris $\mathrm{HCl}$ buffer $\mathrm{pH} 8$ was added and $0.5 \mathrm{ml}$ enzyme added. Run the reaction for 30 minutes. $0.6 \mathrm{ml}$ of ethanol was added and 2 drops of phenol phethalin. $\mathrm{pH}$ of the reaction mix was maintained at $\mathrm{pH} 8.0$ by the addition of small volumes of $50 \mathrm{mM} \mathrm{NaOH}$. The volume of $\mathrm{NaOH}$ used to maintain the $\mathrm{pH}$ was recorded. One unit will hydrolyze 1.0 umol of L-aphosphatidylcholine to L-alysophosphatidylcholine and a fatty acid per hour under standard assay conditions.

\section{RESULTS:}

The genus Candida are imperfect unicellular dimorphic fungi which multiply mainly by budding similar cells from their surface and is composed of an extremely heterogenous group of organisms that grow as yeasts. Most members of the genus also produce a filamentous type of growth (pseudohyphae). C. albicans and C. dubliniensis form true hyphae (germ tubes) and thick-walled cells refered to as chlamydospores this result in figure (1) similar to [13].The principal Candida species according to current nomenclature includes: C. albicans, C. dubliniensis, C. famata, C. glabrata, C. guilliermondii, C. inconspicua, C. kefyr, C. krusei, C. lusitaniae, C. norvegensis, C. parapsilosis, C. rugosa and C. tropicalis as described in [14].

\section{protease activity in Candida species.:}

The five pathogenic isolates were checked quantitively for their ability to produce extracellular different enzymes in sabouraud dextrose liquid media. The data in Figure (4) showed that all of the five different species under investigation secreted proteases at various levels. Purified C.albicans had a maximum protease activities (105.67 \pm 3.66 $\mathrm{U} / \mathrm{ml} / \mathrm{hr}$ ), after $24 \mathrm{hr}$ at $37 \mathrm{oC}$. The other pathogenic species showed an extracellular protease activities range $(86 \pm 2.7$ to $100.75 \mathrm{U} / \mathrm{ml} / \mathrm{hr}$ ). On the other hand, the non-pathogenic species extracellular protease enzyme had significant lower activity.

\section{Phospholipase activity in Candida species.}


The five pathogenic isolates were checked quantitively for their ability to produce extracellular different enzymes in sabouraud dextrose liquid media. The data in figure (5) showed that all of the five different species under investigation secreted phospholipase at various levels. Purified C. glabrata had the maximum phospholipase activities (2.64 \pm 0.192 $\mu \mathrm{mol} / \mathrm{hr}$ ) while other pathogenic species showed an extracellular phospholipase activities rang from $(1.62 \pm 0.21$ to $2.28 \pm$ $0.156 \mu$ mole/hr) after $24 \mathrm{~h}$ at $37 \mathrm{oC}$. Nonpathogenic Candida have very low significant phospholipase activity.

\section{DISCUSSION:}

The incidence of fungal infections, particularly with Candida species, has increased substantially over the past two decades. Candida species have become the fourth leading cause of nosocomial bloodstream infection [15]. Candida was collected from 30 patients admitted to emergency ICU unit and for nonpathogenic candida samples were collected by a sterile cotton swabs from normal individual by the direct scratching of the oral cavity.

In the present study, different methods were used for the identification of different Candida species, Candida isolates were identified and subcultured on morphological medium (cornmeal- Tween 80 agar), subculture on chromogenic medium (CHROMagar Candida) and biochemically using API 20C AUX identification kit.

Cornmeal-Tween 80 absolutely identified all Candida species. These results were in accordance with other findings of Campbell and Richardson who found that in most cases, an examination of morphology on morphologic media to establish the presence or absence of mycelia or pseudomycelia, chlamydospores, and arthrospores was sufficient to make a final identification[16, 17]. Koehler et al suggested that the careful observation of yeast morphology can add confidence to the identification of the commonly encountered species and, more importantly, will alert the microbiologist to the presence of unusual isolates whose misidentification may have serious clinical implications [18].

In the present study, C. albicans and C. tropicalis were absolutely identified on CHROMagar. These results were in agreement with [19-21], who reported that the identification rates were $100 \%$. Walsh stated that CHROM agar was also valuable for the differentiation of mixed cultures which would ordinarily be missed during conventional plating on solid medium [22]. Regarding identification of $\mathrm{C}$. glabrata on CHROMagar many studies showed that CHROMagar could not be used alone for $\mathrm{C}$. glabrata identification because C. kefyr, C. luisitaniae, C. guilliermondii, C. famata, C. rugosa, C. utilis, C. robusta and C. pelliculosa all produce similar type of glossy pink colonies as C. glabrata. On the other hand, all C. glabrata isolates were confirmed by their morphology on Cornmeal-Tween 80 agar and biochemically by API 20C AUX identification kit [18, 21, 23].

Since C. dubliniensis which is very closely related to $\mathrm{C}$. albicans is recently identified as one of a causative agent of Candidiasis. As a result of phenotypic similarities between the two species, many isolates of $\mathrm{C}$. dubliniensis have been misidentified as C. albicans [24].

All the strains of $C$. parapsilosis produced characteristic morphology on Cornmeal agar (satellite colonies from original inoculum) the combination of these two media may identify all the strains of C. parapsilosis within 48 hours [25]. In this study, all C. parapsilosis isolates were confirmed by their morphology on Cornmeal -Tween 80 agar and biochemically by API 20C AUX identification kit.

The most convenient and popular methods for Candida species identification 
consist of strips or plates for carbohydrate assimilation and/or enzyme detection which are commercially available in a variety of different formats [26]. Aubertine and others stated that the API 20 C AUX is considered a reference method among phenotypic tests [27-29]. It requires precision during test implementation, experience in the interpretation of turbidity level and sometimes long incubation times, but it is reliable, easy to use and inexpensive [30].

The five different pathogenic species under investigation secreted proteases at various levels. Purified C.albicans had a maximum protease activities (105.67 \pm $3.66 \mathrm{U} / \mathrm{ml} / \mathrm{hr}$ ), after $24 \mathrm{hr}$ at $37 \mathrm{oC}$. The other pathogenic species showed a high level of extracellular protease activities range $(86 \pm 2.7$ to $100.75 \mathrm{U} / \mathrm{ml} / \mathrm{hr})$. On the other hand, the non-pathogenic Candida had very low significant extracellular protease activity.

This result was similar to RapalaKozik which showed that extracellular proteinases of the candida were considered to be generally destructive factors that damage host tissues and provide nutrients for pathogen propagation [31]. M. RapalaKozik et al also demonstrated that These enzymes play multiple roles in the yeast physiology outside the host organism, contribute to the pathogen adherence to host external surfaces, help to penetrate the host protective barriers and, within the host tissues, are involved in the digestion of host proteins, evasion from the host immune system and propagation of the host inflammatory state. This result doesnot conflict with Pandey which demonstrated that Strong proteinase activity was shown by the $\mathrm{C}$. albicans $(93.75 \%)$, followed by the C. tropicalis $(87.5 \%)$. Strong hemolytic activity was shown by $95.85 \%$ of the C. tropicalis, followed by the C. albicans (81.25\%) [32].

These data were in concomitant with Kantarcioğlu et al [33], they reported that among 95 Candida isolates, 75 (78.94\%) were protease positive. For 60 strains of C. albicans, 57 strains $(95 \%)$ produced.

Naglik et al proved that the aspartyl proteases secreted by Candida play an important role in the virulence of this organism. The roles of this enzyme could range from simple absorption of nutrients until the digestion of the host immunoglobulins to resist the immune system[34]. Amani reported that the incubation of the yeast colonies for 8 days at $37^{\circ} \mathrm{C}$ on agar containing BSA showed that 26 isolates possessed a very high protease activity, 2 have a high activity, 3 isolates have a low activity and 6 have very low or no activity [35].

In our study candida species were checked quantitively for their ability to produce extracellular phospholipase enzyme in sabouraud dextrose liquid media. Purified C.glabrata had a maximum phospholipase activities (2.64 \pm 0.192 $\mu \mathrm{mol} / \mathrm{hr}$ ) after $24 \mathrm{~h}$ at $37 \mathrm{oC}$. The other pathogenic species showed a high level of extracellular phospholipase activities rang from $(1.62 \pm 0.21$ to $2.28 \pm 0.156$ $\mu \mathrm{mole} / \mathrm{hr}$ ) but non-pathogenic Candida have very low significant phospholipase activity $(0.528 \mu \mathrm{mol} / \mathrm{hr})$. these results in concomitant with Kumar et al, they observed that the expression of the phospholipase was high in Candida glabrata isolates of pulmonary tuberculosis patients over the other Candia strains from non tuberculosis individuals [36]. Our results doesn't conflict with Kadir, they observed that the prevalence of C. albicans isolates producing phospholipase varied with the specific isolate and correlated with site or type of infection and with presence of some systemic diseases[37]. On the other hand this result doesn't agree with Pandey et al, they showed that phospholipase and proteinase were produced by a higher number of the $\mathrm{C}$. albicans strain[32].

\section{CONCLUSION:}


With our current observation of the increased extracellular proteases and phospholipase after the opportunistic attack of the candida growth on patients admitted to emergency ICU unit and The increased incidence of candidal infections in recent decades has been associated with the global increase of fungal resistance to available drugs, To improve currently available therapeutic strategies, researchers and clinicians should pay special attention to extracellular candidal proteases and phospholipase that appear to represent the best candidates as targets for therapeutic drugs, because of the broad spectrum of their engagements in the pathology of both superficial and invasive candidiasis.

\section{REFERENCES:}

1. Carrillo-Munoz, A., et al., 2008, Activity of caspofungin and voriconazole against clinical isolates of Candida and other medically important yeasts by the CLSI M-44A disk diffusion method with Neo-Sensitabs tablets. Chemotherapy. 54: p. 38-42.

2. Conti, H.R. and S.L. Gaffen, 2015, IL-17-Mediated immunity to the opportunistic fungal pathogen Candida albicans. The Journal of Immunology. 195: p. 780-788.

3. Tellapragada, C., et al., 2014, Antifungal susceptibility patterns, in vitro production of virulence factors, and evaluation of diagnostic modalities for the speciation of pathogenic Candida from blood stream infections and vulvovaginal candidiasis. Journal of pathogens. 2014.

4. Bitrus, A., et al., 2018, Dissemination of resistance and virulence determinants in methicillin-resistant

Staphylococcus aureus during colonization and disease. A
Review. Adv. Anim. Vet. Sci. 6: p. 44-54.

5. Calderone, R.A. and W.A. Fonzi, 2001, Virulence factors of Candida albicans. Trends in microbiology. 9: p. 327-335.

6. Sardi, J., et al., 2013, Candida species: current epidemiology, pathogenicity, biofilm formation, natural antifungal products and new therapeutic options. Journal of medical microbiology. 62: p. 1024.

7. Noumi, E., et al., 2015, Phenotypic characterization and adhesive properties of vaginal Candida spp. strains provided by the CHU Farhat Hached (Sousse, Tunisia). Revista iberoamericana de micologia. 32: p. 170-179.

8. Lima, P., et al., 2016, Salivary Lactoferrin in HIV-Infected Children: It's Importance on Antifungal Activity against Oral Candida Albicans Infections. Austin J HIV. AIDS Res. 3: p. 1032.

9. Jalal, M., et al., 2018, Anticandidal activity of bioinspired $\mathrm{ZnO}$ NPs: effect on growth, cell morphology and key virulence attributes of Candida species. Artificial cells, nanomedicine, and biotechnology: p. 1-14.

10. Pereira, C.A., et al., Candida albicans and virulence factors that increases its pathogenicity, in The battle against microbial pathogens: basic science, technological advances and educational programs. 2015, Formatex Research Center.

11. Dostál, J., et al., 2003, Simple method for screening Candida species isolates for the presence of secreted proteinases: a tool for the prediction of successful inhibitory treatment. Journal of clinical microbiology. 41: p. 712-716.

12. Badawi, H., et al., 2004, Candida urinary infections: emerging 
species, anti-fungal Susceptibility trends and antibody response. Egypt J. Med. Microbiol. 13: p. 114.

13. Miller, A.S. and R.W. Wilmott, The Pulmonary Mycoses, in Kendig's Disorders of the Respiratory Tract in Children (Ninth Edition). 2019, Elsevier. p. 507-527. e3.

14. Cabra-Rodriguez, R., A. Tenorio-Abreu, and I. ZakariyaYousef Breval, 2018, [Candida parapsilosis infection in a corneal transplant patient]. Rev Esp Quimioter.

15. Wisplinghoff, H., et al., 2004, Nosocomial bloodstream infections in US hospitals: analysis of 24,179 cases from a prospective nationwide surveillance study. Clinical infectious diseases. 39: $\mathrm{p}$. 309-317.

16. RICHARDSON, M.D., 2002, Culture-and non-culture-based diagnostics for Candida species. Candida and candidiasis: p. 387394.

17. Campbell, C.K., et al., 1999, Comparison of the API Candida system with the AUXACOLOR system for identification of common yeast pathogens. Journal of clinical microbiology. 37: p. 821-823.

18. Koehler, A.P., et al., 1999, Simple, reliable, and cost-effective yeast identification scheme for the clinical laboratory. Journal of clinical microbiology. 37: p. 422426.

19. Yucesoy, M., A. Oztek, and S. Marol, 2005, Comparison of three differential media for the presumptive identification of yeasts. Clinical microbiology and infection. 11: p. 245-247.

20. Fotedar, R. and S. Al- Hedaithy, 2003, Identification of chlamydospore- negative Candida albicans using CHROMagar
Candida medium. Mycoses. 46: p. 96-103.

21. Hospenthal, D.R., et al., 2006, Presumptive identification of Candida species other than $C$. albicans, C. krusei, and $C$. tropicalis with the chromogenic medium CHROMagar Candida. Annals of clinical microbiology and antimicrobials. 5: p. 1.

22. Walsh, T.J., et al., 2008, Treatment of aspergillosis: clinical practice guidelines of the Infectious Diseases Society of America. Clinical infectious diseases. 46: p. 327-360.

23. Murray, M.P., R. Zinchuk, and D.H. Larone, 2005, CHROMagar Candida as the sole primary medium for isolation of yeasts and as a source medium for the rapidassimilation-of-trehalose test. Journal of clinical microbiology. 43: p. 1210-1212.

24. Coronado-Castellote, $L$. and $Y$. Jiménez-Soriano, 2013, Clinical and microbiological diagnosis of oral candidiasis. Journal of clinical and experimental dentistry. 5: $\mathrm{p}$. e279.

25. Baradkar, V., M. Mathur, and S. Kumar, 2010, Hichrom candida agar for identification of Candida species. Indian Journal of Pathology and Microbiology. 53: p. 93.

26. Ellepola, A.N. and C.J. Morrison, 2005, Laboratory diagnosis of invasive candidiasis. The Journal of Microbiology. 43: p. 65-84.

27. Aubertine, C., et al., 2006, Comparative study of the new colorimetric VITEK 2 yeast identification card versus the older fluorometric card and of CHROMagar Candida as a source medium with the new card. Journal of clinical microbiology. 44: $\mathrm{p}$. 227-228. 
28. Hata, D.J., et al., 2007, Multicenter evaluation of the new VITEK 2 advanced colorimetric yeast identification card. Journal of clinical microbiology. 45: p. 10871092.

29. Asticcioli, S., et al., 2009, Trends in frequency and in vitro antifungal susceptibility patterns of Candida isolates from women attending the STD outpatients clinic of a tertiary care hospital in Northern Italy during the years 2002-2007. The new microbiologica. 32: p. 199.

30. Liguori, G., et al., 2010, Candida albicans identification: comparison among nine phenotypic systems and a multiplex PCR. Journal of preventive medicine and hygiene. 51.

31. Rapala-Kozik, M., et al., 2018, Extracellular proteinases of Candida species pathogenic yeasts. Molecular oral microbiology. 33: p. 113-124.

32. Pandey, N., M.K. Gupta, and R. Tilak, 2018, Extracellular hydrolytic enzyme activities of the different Candida spp. isolated from the blood of the Intensive Care Unit-admitted patients. Journal of laboratory physicians. 10: p. 392.

33. Kantarcioğlu, A.S. and A. Yücel, 2002, Phospholipase and protease activities in clinical Candida isolates with reference to the sources of strains: Phospholipaseand Protease-Aktivitat bei klinischenCandida-Isolaten mit Bezug zur Herkunft der Stämme. Mycoses. 45: p. 160-165.

34. Naglik, J.R., S.J. Challacombe, and B. Hube, 2003, Candida albicans secreted aspartyl proteinases in virulence and pathogenesis. Microbiol. Mol. Biol. Rev. 67: p. 400-428.

35. Amani, D., et al., 2018, Extracellular enzymes and adhesive properties of medically important Candida spp. strains from landfill leachate. Microbial pathogenesis. 116: p. 328-334.

36. Kumar, V.G., et al., 2009, Phospholipase $C$, proteinase and hemolytic activities of Candida spp. isolated from pulmonary tuberculosis patients. Journal de Mycologie Médicale. 19: p. 3-10.

37. Kadir, T., B. Gümrü, and B. Uygun-Can, 2007, Phospholipase activity of Candida albicans isolates from patients with denture stomatitis: the influence of chlorhexidine gluconate on phospholipase production. Archives of oral biology. 52: p. 691-696.
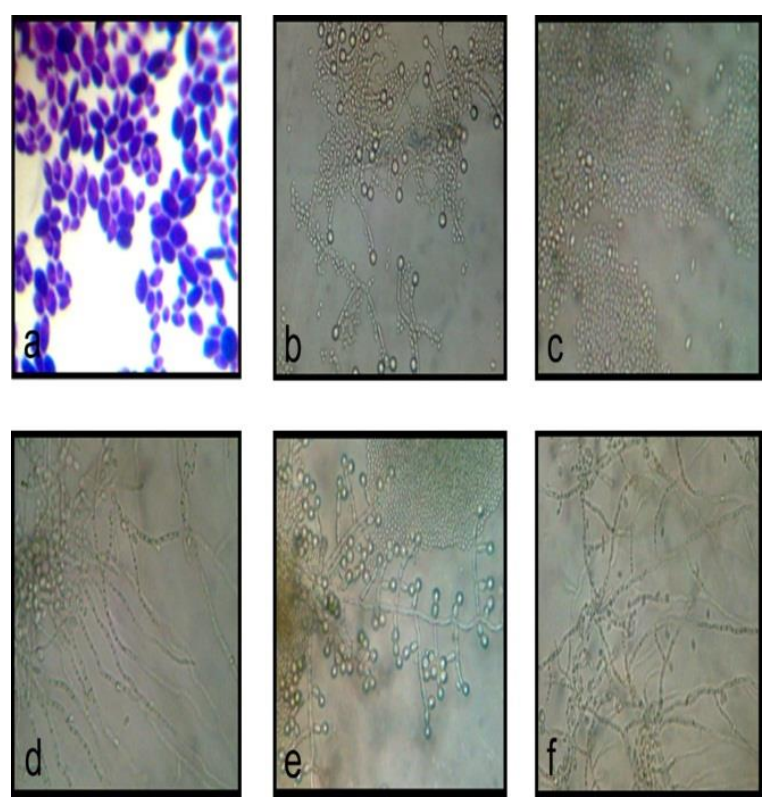

Figure 1(a) microscopic apperance of Candida stained by gram stain, (b) Microscopic appearance of C. albicans on Corn meal Agar Tween 80 showing yeast cells, pseudohyphae and chlamydospores, (c) Microscopic appearance of C. glabrata on Cornmeal Tween 80 Agar showing blastoconidia only with no pseudohyphae or hyphae, (d) Microscopic appearance of C. tropicalis on Cornmeal Tween 80 Agar showing abundant pseudohyphae radiating with clusters of blastoconidia at the center (Magnification X400), (e) Microscopic appearance of $C$. dubliniensis on Cornmeal Tween 80 Agar showing yeast cells, pseudohyphae and abundant (clusters) chlamydospores, (f) Microscopic appearance of $\mathrm{C}$. parapsilosis on Cornmeal Tween 80 Agar showing branched chains of pseudohyphae with blastoconidia along them (Magnification X400) 
Table 1: Different strains of candida on chrome agar

\begin{tabular}{|l|l|}
\hline $\begin{array}{l}\text { Candida } \\
\text { Species }\end{array}$ & $\begin{array}{l}\text { Colony Color on CHROM } \\
\text { Agar }\end{array}$ \\
\hline C. albicans & Apple green colonies. \\
\hline C. glabrata & $\begin{array}{l}\text { Large pale pink to purple } \\
\text { glossy colonies. }\end{array}$ \\
\hline C. tropicalis & $\begin{array}{l}\text { Metallic blue, sometimes pink } \\
\text { colonies, all developed purple } \\
\text { halo pigment that diffused into } \\
\text { surrounding agar. }\end{array}$ \\
\hline C. dubliniensis & Dark green colonies. \\
\hline C. parapsilosis & $\begin{array}{l}\text { Off-white to pale pink } \\
\text { colonies. }\end{array}$ \\
\hline
\end{tabular}
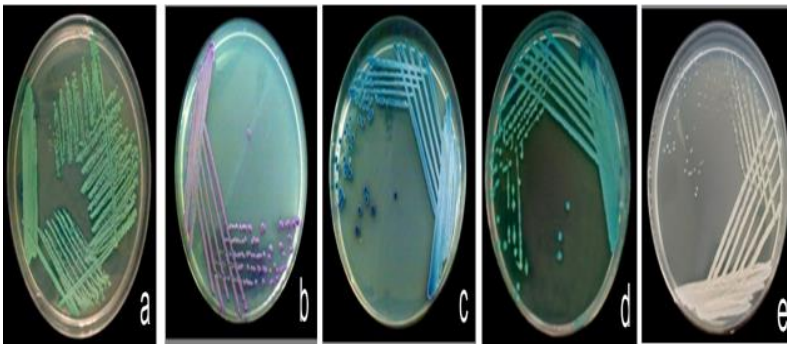

Figure 2 Different strains of candida on chrome agar. (a) C. albicans, (b) C. glabrata, (c) C. tropicalis, (d) C. dubliniensis, (e) C. parapsilosis.

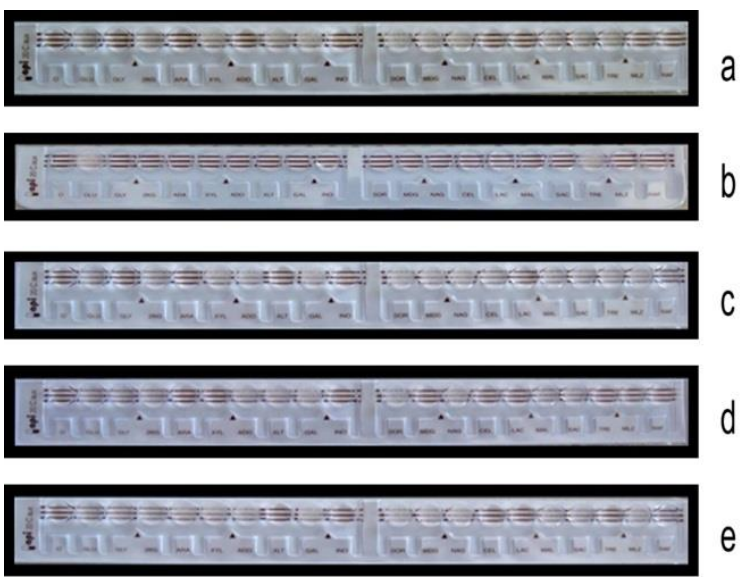

Figure 3 API 20C AUX of different

Candida species. (a) C. albicans, (b) C.

glabrata, (c) C. tropicalis, (d) C. dubliniensis, (e) C. parapsilosis.

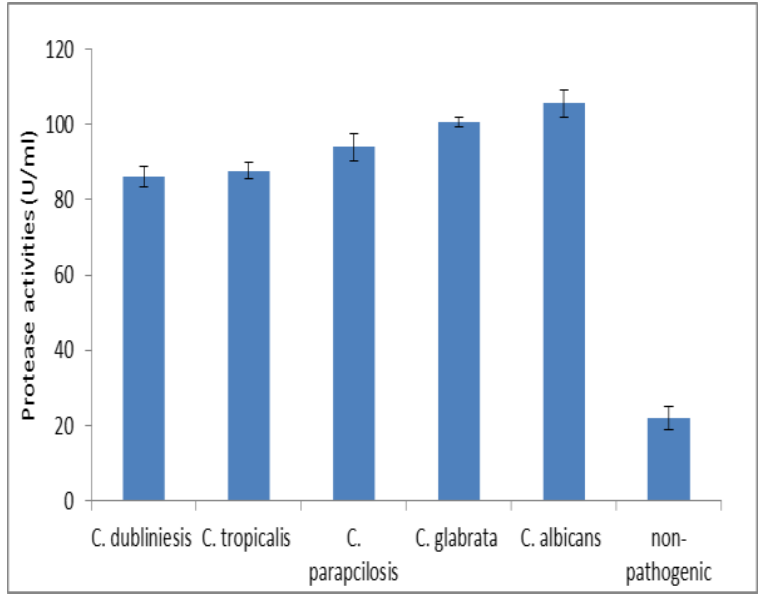

Figure 4 Protease activities from six different candida.

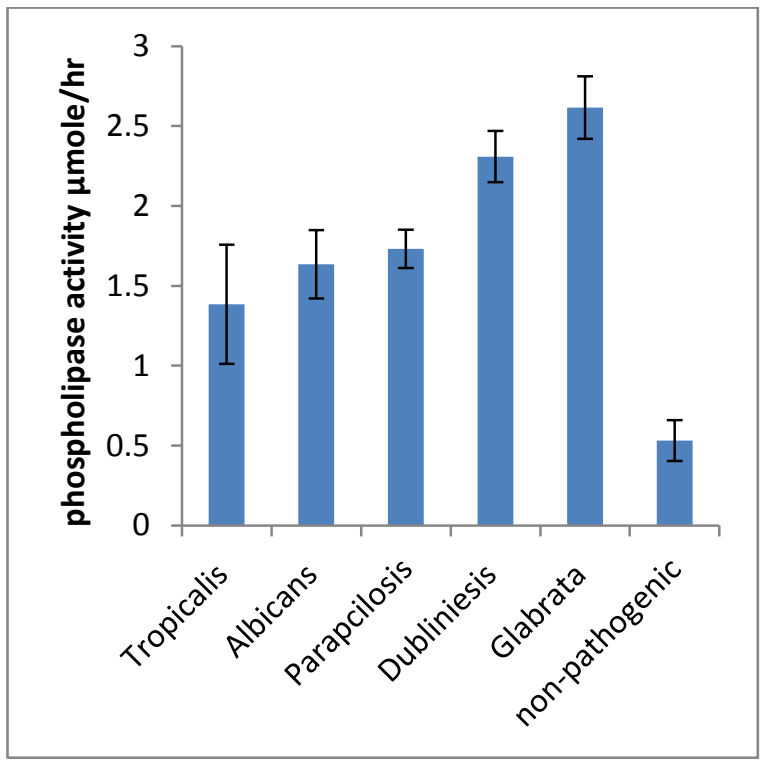

Figure 5 phospholipase activities from six different Candida species. 